\title{
Comparison of quality characteristics between compound and pure milk chocolate
}

\begin{abstract}
Cocoa butter substitute (CBS) base compound chocolate presents outstanding problems associated with a poor tolerance between CBS and cocoa butter (CB). This study focuses on the determination of the best blend (CBS: $\mathrm{CB}$ ) of compound milk chocolate which has a similar characteristic as pure milk chocolate. The analysis includes color (Hunter Lab), fatty acid content (gas chromatography/GC), melting properties (Differential Scanning Calorimetry/DSC) and texture. Color (L value) of the compound chocolate (ratio of 20:80) was significantly $(\mathrm{p}<0.05)$ darker $(25.50 \pm 0.20)$ than pure milk chocolate (27.22 \pm 0.32$)$. GC analysis shows decreased of total lauric acid $(41.17,36.49,23.77,26.43$, 2.88 and 2.12 respectively) with the increased of $\mathrm{CB}(0 \%$ to $100 \%)$ and decreased of CBS $(100 \%$ to $0 \%)$. DSC analysis also shows increased of CB addition (100:0, 60:40 and 40: 60) in compound milk chocolate caused significant $(\mathrm{p}<0.05)$ reduction of $\mathrm{T}_{\text {peak }}$ value $\left(35.37^{\circ} \mathrm{C} \pm 0.05,33.90^{\circ} \mathrm{C} \pm 0.00\right.$ and $30.24^{\circ} \mathrm{C} \pm 0.13$ respectively) compared to pure milk chocolate $\left(29.96^{\circ} \mathrm{C} \pm 0.00\right)$. The ratio $20: 80$ of compound milk chocolate shows similar quality characteristic as pure milk chocolate in terms of fatty acid composition (lauric acid $2.88 \%$ ) and hardness (2832.3 \pm 8.88 ). This finding highlights the application of CB and CBS blend in compound milk chocolate which may provide the best alternatives to the chocolate producer.
\end{abstract}

Keywords: cocoa butter, cocoa butter substitutes, melting profiles, milk chocolate and fatty acids
Volume 6 Issue 3 - 2018

\section{Norhayati Hussain, Baizura Aya Putri Agus, Siti Nur Fifi Abdul Rahim, Halimatun Sa'adiah Abdul Halim}

Department of Food Technology, Universiti Putra Malaysia, Malaysia

\author{
Correspondence: Norhayati Hussain, Department of \\ Food Technology, Faculty of Food Science and Technology, \\ Universiti Putra Malaysia, 43400 Serdang, Selangor, Malaysia, Tel \\ +60389468536, Fax +60389485970, \\ Email aryatihussain@upm.edu.my
}

Received: September 0I, 2017 | Published: May 302018
Abbreviations: CBS, cocoa butter substitute; GC, gas chromatography; DSC, differential scanning calorimetry; SMUT, symmetric mono unsaturated triacylglycerols; PO, palm olein

\section{Introduction}

Cocoa butter (CB) is an essential ingredient in the chocolate production. The great symmetric mono unsaturated triacylglycerols (SMUT) content (about $80 / 100 \mathrm{~g}$ ) of CB is responsible for its unique physical characteristics, such as the dominating existence of stable $\beta$ crystals and rapid melting at body temperature, thus provides chocolate with good snap, gloss and smooth mouthfeel. Chocolates are typically sweet, and it is one of the most popular food types and flavors in the world. Main commercial chocolate categories are dark, milk and white chocolates which differ in their content of cocoa solids, milk fat and cocoa butter. Jahurul et al. ${ }^{1}$ stated that milk chocolate appears to be favored throughout the United States compared to any other chocolate type. In 2012, over 50percent consumers preferred milk chocolate compared to any other chocolate types. Therefore, milk chocolate has always been a firm favorite in the world.

Many leading chocolate producers such as Hershey uses cocoa butter alternatives (CBAs) derived from Shea butter, palm oil or other sources to replace partially the cocoa butter. Other researchers have also carried out production of cocoa butter replacers (CBRs), cocoa butter equivalents (CBEs) and cocoa butter substitutes (CBSs) from various natural sources. All of these fats are obtained from a natural plant such as palm kernel oil (PKO), palm olein (PO), mango seed fat, soy oil, rapeseed oil, cotton oil, groundnut oil and coconut oil. ${ }^{1}$ Lauric CBS is economical vegetable fat to replace $\mathrm{CB}$ and have physical properties resembling those of $\mathrm{CB}$. On the other hand, lauric $\mathrm{CBS}$ is used to replace a major part of the cocoa butter $(\mathrm{CB})$ that is present in pure chocolate.
Unfortunately, chocolate made of fully CBS lacks the pleasant flavor that is typical of pure chocolate made of fully CB. The introduction of $\mathrm{CB}$ into $\mathrm{CBS}$ base chocolate may enhance the flavor, making it more desirable to the consumer. However, such CBS base compound chocolate presents outstanding problems associated with a poor tolerance between CBS and $\mathrm{CB}$. The binary fat mixture and the corresponding chocolates have been extensively studied. ${ }^{2,3}$ A mix of CBS with CB may result in a eutectic state that will lead to softening and phase separation of chocolate products. ${ }^{4}$ This incompatibility is due to the significant difference in the fatty acid (FA) compositions and distributions between $\mathrm{CB}^{5}$ and the substitutes.

Researchers are still investigating the best formulation, a method of extraction, physical properties, rheological behavior and sensory perception of the compound chocolate. However, less information is available on determining the quality characteristic of compound chocolate after blending the $\mathrm{CB}$ with CBS. Therefore, the general objective of this study was to compare the quality characteristics of the compound milk chocolate blended with different ratio of CBS and CB with pure milk chocolate.

\section{Materials and methods}

There were six types of milk chocolate samples produced at Malaysian Cocoa Board, Nilai as shown in Figure 1. The ingredients used in the chocolate formulation included sugar, cocoa butter and cocoa liquor were purchased from Barry Callebaut Services Asia Pacific Sdn. Bhd., Port Klang, Selangor. Cocoa butter substitute (CBS) was purchased from MOI Food Sdn. Bhd., Port Klang, Selangor whereas full cream milk powder was purchased from Yummies Bakery Sdn. Bhd., Bandar Baru Bangi, Selangor. Table 1 shows formulation of the milk chocolate used in this study by referring to De Clercq et al. ${ }^{6}$ 
Table I Formulations of compound and pure milk chocolates

\begin{tabular}{|c|c|c|c|c|c|c|}
\hline Ratio (CBS: CB)/Ingredients & $\begin{array}{l}\text { Pure milk chocolatel } \\
\text { Control }(0: 100)\end{array}$ & $20: 80$ & $40: 60$ & $60: 40$ & $80: 20$ & $100: 0$ \\
\hline Cocoa liquor & 9 & 9 & 9 & 9 & 9 & 9 \\
\hline Cocoa butter & 26 & 21 & 16 & 10 & 5 & - \\
\hline Cocoa butter substitute (CBS) & - & 5 & 10 & 16 & 21 & 26 \\
\hline Full cream milk powder, sugar and lecithin & 65 & 65 & 65 & 65 & 65 & 65 \\
\hline Total & 100 & 100 & 100 & 100 & 100 & 100 \\
\hline
\end{tabular}

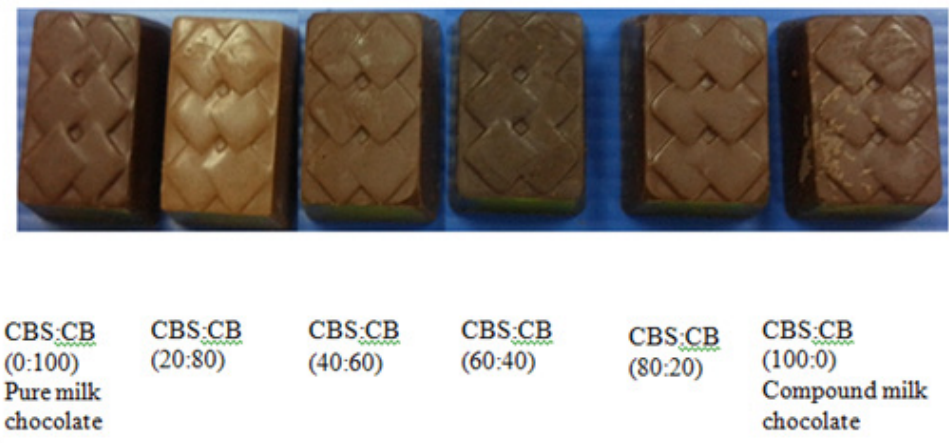

Figure I Compound and pure milk chocolate containing different compositions of cocoa butter and cocoa butter substitute.

First, all of the ingredients for making the chocolates were mixed. The mixture of sugar, cocoa mass and cocoa butter need to be refined to a particle size of less than $30 \mu \mathrm{m}$. After refining, the mixture was transferred to the conche (Pascal Engineering, England) for conching process and then manually tempered. It is important to temper the pure milk chocolate before moulding. However, the compound chocolate does not require tempering process. Approximately $2000 \mathrm{~g}$ of chocolate was produced at every production cycle. The compound and pure milk chocolate were stored at a chill temperature $\left( \pm 16^{\circ} \mathrm{C}\right)$ for four weeks until further analysis. Before performing the analysis, the chocolates were melted in an oven (Memmert, Germany) at $45^{\circ} \mathrm{C}$.

\section{Analysis of chocolates}

\section{Texture analysis}

Hardness or degree of chocolate softening was measured by determining the maximum penetration force. A Texture Analyser Model TA-XT2I (UK) was used to measure the depth of penetration of samples using the following parameters: Product height $=10 \mathrm{~mm}$, penetration depth $=6 \mathrm{~mm}$; probe needle PN2, temperature $20^{\circ} \mathrm{C}$, prespeed $1.0 \mathrm{~mm} / \mathrm{s}$, test speed $=1.1 \mathrm{~mm} / \mathrm{s}$, post speed $=10.0 \mathrm{~mm} / \mathrm{s}$ and the duration time of the test took approximately 1 to $2 \mathrm{~min} .{ }^{8}$

\section{Color analysis}

Hunter Lab Miniscan ${ }^{\mathrm{TM}}$ XE Colorimeter Model 45/0LAV (Hunter Associates Inc., Reston, VA) calibrated with white ceramic reference standard was used to compare the color between chocolate sample. Color images of the chocolate surfaces were converted into XYZ tristimulus values, which were further converted to CIELAB system: The $\mathrm{L}^{*}$ values represent lightness of color from 0 (black) to 100 (white), $a^{*}$ values represent the degree of redness $(+)$ or greenness $(-)$, and $b^{*}$ values represent yellowness $(+)$ or blueness $(-)$.

\section{Melting properties}

Each type of the chocolate melting profiles was determined using Differential scanning calorimeter (DSC). The DSC is equipped with a thermal analysis data station and calibrated using indium and octadecane at a scan rate of $5^{\circ} \mathrm{C} / \mathrm{min}$ using an aluminium pan as a reference. Samples $(\sim 5 \mathrm{mg})$ were loaded into $40 \mu 1$ capacity pans with holes, which were sealed with lids using a sample press. Pans were heated at $5^{\circ} \mathrm{C} / \mathrm{min}$ from $15-55^{\circ} \mathrm{C}$ in an $\mathrm{N}_{2}$ stream. Onset temperature $\left(\mathrm{T}_{\text {onsel }}\right)$, peak temperature $\left(\mathrm{T}_{\text {peak }}\right)$, end temperature $\left(\mathrm{T}_{\text {end }}\right)$ and enthalpy of melting $\left(\Delta \mathrm{H}_{\text {melt }}\right)$ were calculated automatically by the software. Melting index ( $\left(\mathrm{T}_{\text {index }}\right)$ was computed as $\left(\mathrm{T}_{\text {end }}-\mathrm{T}_{\text {onset }}\right)$, and measures duration of melting as described by Vasanthan \& Bhatty ${ }^{9}$ and Afoakwa et al. ${ }^{10}$ Each sample was analyzed in triplicate whereas mean values, and standard deviations ware also reported.

\section{Fatty acid methyl esters analysis}

The chocolate fatty acid profile was determined according to AOCS Ce 1b-89. ${ }^{11}$

\section{Statistical analysis}

Statistical analysis was performed using Minitab. The one-way analysis of variance (ANOVA) was employed while the significance was established using Tukey posthoc test. The probability level of $p<0.05$ was considered significant. All data were expressed as means \pm standard deviations (SD) of the values obtained. ${ }^{1}$

\section{Results and discussion}

\section{Texture analysis}

A penetration test was performed to evaluate the hardness of the milk chocolate bars. A milk chocolate bar was placed on the plate, and the probe penetrated the chocolate at $6 \mathrm{~mm}$ depth. Hardness was 
defined as the force required compressing a bolus of milk chocolate at $75 \%$ deformation. ANOVA (Table 2) shows there was a significant $(\mathrm{p}<0.05)$ different of the hardness of compound and pure milk chocolate containing a different ratio of $\mathrm{CB}$ and $\mathrm{CBS}$.

Table 2 Texture values for compound and pure milk chocolate containing different compositions of cocoa butter (CB) and cocoa butter substitutes (CBS)

\begin{tabular}{ll}
\hline Formulation (CBS:CB) & Hardness (g.sec) \\
\hline Compound milk chocolate (100:0) & $2954.4 \pm 22.5^{\mathrm{b}}$ \\
$80: 20$ & $1886.2 \pm 6.0^{\mathrm{c}}$ \\
$60: 40$ & $1466.3 \pm 44.6^{\mathrm{e}}$ \\
$40: 60$ & $1646.9 \pm 0.17^{\mathrm{d}}$ \\
$20: 80$ & $2832.3 \pm 8.88^{\mathrm{b}}$ \\
Pure milk chocolate $(0: 100)$ & $3301.5 \pm 96.4^{\mathrm{a}}$ \\
\hline
\end{tabular}

Chocolate made of hard lauric butter is very sensitive to the presence of CB. ${ }^{12,13}$ Addition of $\mathrm{CB}$ in compound chocolates had increased its hardness but softer than pure milk chocolate. Moreover, Williams et al. ${ }^{14}$ showed that mixing of CBS with CB resulted in a eutectic state which leads to a softening and phase separation of chocolate products. The effect remains unexplored.

\section{Color analysis}

The color of foods may be affected by various optical phenomena such as scattering and surface morphology. Therefore, an accurate understanding of the influence of surface topography on measured color is essential. ${ }^{15}$ The color was expressed following the CIEL*a*b*system. The color measurement shows there was a significant $(\mathrm{p}<0.05)$ different in color between the compound and pure milk chocolate. The lower values for $\mathrm{L}^{*}$ (lightness) indicates darker appearance than a higher value. The ratio of 60:40 (CBS: CB) shows the lowest $\mathrm{L}^{*}$ mean value $25.50 \pm 0.20$ which was darker than pure milk chocolate $(27.22 \pm 0.32)$ and the appearance can also be referred to Figure 1. The difference in color between 60:40 ratio and pure milk chocolate might be due to the significant difference in the original color of both $\mathrm{CB}$ and CBS. The color seen by the naked eye was dark yellow for CB whereas CBS were white in color. However, the ratio of 100:0 (27.66 \pm 0.82$)$ and 80:20 (28.04 \pm 0.48$)$ show insignificant $(\mathrm{p}>0.05)$ difference in color compared to pure milk chocolate.

The color differences of the fats samples influence the color of the compound and pure milk chocolate. ${ }^{16}$

Liesbeth $^{16}$ study shows the lightness $\mathrm{L}^{*}$ value ranged from 26.80 to 27.75 ; $\mathrm{a}^{*}$ value ranged from 6.18 to 6.48 and $\mathrm{b}^{*}$ value ranged from 4.16 to 4.48 for formulated vegetable fats (CBE) added with $\mathrm{CB}$. The formation of a crystal network with varying particle sizes also gives rise to scattering of the light and reduces the lightness of a chocolate made from cocoa butter. ${ }^{8}$ Due to the difference in crystallization properties, the crystal network could be influenced and giving rise to a difference in lightness of the compound and pure milk chocolate (Table 3).

\section{Melting characteristics of chocolate compound}

The importance of the determination of the melting character in finished products is the crystalline state and the proportion of solid fat present during chocolate manufacture. The chocolate melting profiles characterize changes and measures the relative amounts of each crystalline state using DSC. ${ }^{17-20}$ Peak onset $\left(\mathrm{T}_{\text {onse }}\right)$ corresponds to the temperature at which a specific crystal form starts to melt whereas peak maximum $\left(\mathrm{T}_{\text {peak }}\right)$ corresponds to the greatest melting rate occurrence and end of melting $\left(\mathrm{T}_{\text {end }}\right)$ shows completion of liquefaction. All these information are related to crystal type of cocoa butter. ${ }^{21}$

Table 3 Color measurements ( $\mathrm{L}$, $\mathrm{a}$ and $\mathrm{b}$ values) of the compound and pure milk chocolate

\begin{tabular}{llcc}
\hline Formulation (CBS:CB) & $\mathbf{L}$ & $\mathbf{a}$ & $\mathbf{b}$ \\
\hline $100: 0$ & $27.66 \pm 0.82^{\mathrm{c}}$ & $6.09 \pm 0.13^{\mathrm{c}}$ & $6.36 \pm 0.25^{\mathrm{b}}$ \\
$80: 20$ & $28.04 \pm 0.48^{\mathrm{c}}$ & $6.40 \pm 0.22^{\mathrm{b}}$ & $6.42 \pm 0.30^{\mathrm{b}}$ \\
$60: 40$ & $25.50 \pm 0.20^{\mathrm{d}}$ & $5.17 \pm 0.09^{\mathrm{e}}$ & $4.48 \pm 0.10^{\mathrm{d}}$ \\
$40: 60$ & $29.55 \pm 0.26^{\mathrm{b}}$ & $6.63 \pm 0.07^{\mathrm{b}}$ & $6.72 \pm 0.08^{\mathrm{b}}$ \\
$20: 80$ & $36.75 \pm 0.5 \mathrm{I}^{\mathrm{a}}$ & $8.32 \pm 0.14^{\mathrm{a}}$ & $10.13 \pm 0.15^{\mathrm{a}}$ \\
Pure milk chocolate $(0: 100)$ & $27.22 \pm 0.32^{\mathrm{c}}$ & $5.59 \pm 0.20^{\mathrm{d}}$ & $5.38 \pm 0.14^{\mathrm{c}}$ \\
\hline
\end{tabular}

a,b,c,d Different letter indicates significant different between rows under same column

In this study, melting of the compound and pure milk chocolate had caused a negative (endothermic) heat effect. The peak is an interpretation of change in the differential heat flow, which is caused by the changes in the samples associated with absorption or evolution of heat. There is a direct correlation between the area under the peak and enthalpic change, and this direction will indicate whether the thermal event is endothermic or exothermic. ${ }^{22}$

Increased of $\mathrm{CB}$ addition from 80:20 to 0:100 (CBS: $\mathrm{CB}$ ) caused significant $(\mathrm{p}<0.05)$ reductions in $\mathrm{T}_{\text {end }}$ value from 40.13 to $37.13^{\circ} \mathrm{C}$. These explained that higher CBS in milk chocolate required a longer time to melt than pure milk chocolate that has fully $\mathrm{CB} .{ }^{23}$ Wang et al. ${ }^{23}$ found that eutectic effect existed, and Tend ranged from 40 to $45^{\circ} \mathrm{C}$ in the mixture of $\mathrm{CB}$ and $\mathrm{CBS}$. This finding indicates the importance of the different components of $\mathrm{CB}$ and $\mathrm{CBS}$ in milk chocolate and how it can be fully exploited for application in milk chocolate. The DSC (Table 4) indicates that varying composition of CB and CBS produced changes in melting properties as observed in the different of the peak widths.

The $\mathrm{T}_{\text {peak }}$ for $\mathrm{CB}$ with melting rate at $29.96^{\circ} \mathrm{C}$ was similar to the previous study who also stated that melting of cocoa butter takes place from 15 to $36^{\circ} \mathrm{C}$, depending on the polymorphic form..$^{24}$ The steepness of the curve of the cocoa butter contributes to the flavor release. The flavor is released in a relatively short time leading to an intense flavor because of its melting profiles. Next, to the flavor release, the sharp melting profile handles the cooling sensation in the mouth, due to heat absorbed by the fat to melt. ${ }^{25}$ The pure milk chocolates began to melt easily than the compound chocolate. However, the ratio of 80:20 (CBS: CB) showed insignificant $(\mathrm{p}>0.05)$ Tpeak value $\left(29.97^{\circ} \mathrm{C}\right)$ compared to pure milk chocolate $\left(29.96^{\circ} \mathrm{C}\right)$. This knowledge is important as it provides information on likely oral melting behavior with an impact on temporal components of flavor release and also oral epithelial sensation. ${ }^{26}$

\section{Fatty acid methyl esters analysis}

The fatty acid composition of fat is one of the most important 
parameters to govern the physical properties as well as the polymorphic behavior of the fat. ${ }^{4}$ The fatty acid analysis of the compound and pure milk chocolate show that the milk chocolate with $100 \%$ CBS and $0 \%$ CB had significantly $(\mathrm{p}<0.05)$ the highest composition of lauric acid (41.15\%) and myristic acid (14.51\%). However, it has the lowest percentage of oleic acid $(7.15 \%)$ and linoleic acid $(2.39 \%)$ which are the dominant unsaturated fatty acids as compared to others (Table 5). In addition, saturated fatty acids include three types of fatty acids, namely lauric $\left(\mathrm{C}_{12}: 0\right)$, myristic $\left(\mathrm{C}_{14}: 0\right)$, and stearic $\left(\mathrm{C}_{18}: 0\right)$ acids, while unsaturated fatty acids include two types of fatty acids, namely oleic $\left(\mathrm{C}_{18}: 1\right)$ and linoleic $\left(\mathrm{C}_{18}: 2\right)$ acids. Other fatty acids were also present in the milk chocolate in a small amount. ${ }^{27}$

From Table 5 , the major fatty acids found in the compound and pure milk chocolate were lauric acid, palmitic acid, stearic acid and oleic acid. Increased of $(0 \%-100 \%) \mathrm{CB}$ and decreased of $(100 \%-0 \%) \mathrm{CBS}$ in the blends have caused a gradual increased of the total stearic acid $(18.20,22.11,22.18,20.50,30.68$ and 30.96 respectively). Meanwhile, the amount of lauric acid was found to gradually decreased (41.17, $36.49,23.77,26.43,2.88$ and 2.12 respectively) with the increased $(0 \%-100 \%)$ of CB and decreased the content of CBS for $(100 \%-0 \%)$. The lauric acid contributes to soapy taste to the compound chocolate. A soapy taste found in a compound chocolate based made of CBSs can only occur in the presence of a lipase and sufficient water. ${ }^{28}$ The composition of the different fatty acid varies with the origin of the $\mathrm{CB}$ thus the natural variations were considered. ${ }^{29}$ In addition, the variations within a single country can also be significant as a function of crop, or region. These variations affect the fatty acid composition of the chocolate, hard or soft texture, and that the texture is a direct result of the fatty acid composition. ${ }^{30}$

Table 4 Melting properties of compound and pure milk chocolate containing different composition of cocoa butter (CB) and cocoa butter substitutes (CBS)

\begin{tabular}{|c|c|c|c|c|}
\hline Formulation (CBS:CB) & $\mathrm{T}_{\text {onset }}\left({ }^{\circ} \mathrm{C}\right)$ & $\mathrm{T}_{\text {end }}\left({ }^{\circ} \mathrm{C}\right)$ & $\mathrm{T}_{\text {peak }}\left({ }^{\circ} \mathrm{C}\right)$ & $\Delta \mathbf{H}_{\text {melt }}(J / g)$ \\
\hline $100: 0$ & $27.53 \pm 0.04^{\text {cd }}$ & $39.38 \pm 0.02^{\mathrm{ab}}$ & $35.37 \pm 0.05^{\mathrm{a}}$ & $25.66 \pm 0.30^{\mathrm{a}}$ \\
\hline $80: 20$ & $27.64 \pm 0.08^{\mathrm{bc}}$ & $40.13 \pm 0.59^{a b}$ & $29.97 \pm 0.09^{d}$ & $12.74 \pm 0.69^{b}$ \\
\hline $60: 40$ & $27.7 I \pm 0.05^{b}$ & $42.67 \pm 0.28^{\mathrm{a}}$ & $33.90 \pm 0.00^{\mathrm{b}}$ & $25.35 \pm 1.04^{\mathrm{a}}$ \\
\hline $40: 60$ & $27.72 \pm 0.08^{\mathrm{ab}}$ & $40.49 \pm 3.02^{\mathrm{ab}}$ & $30.24 \pm 0.13^{c}$ & $12.48 \pm 3.70^{b}$ \\
\hline $20: 80$ & $27.86 \pm 0.04^{a}$ & $37.70 \pm 2.24^{\mathrm{b}}$ & $30.08 \pm 0.13^{\mathrm{cd}}$ & $8.82 \pm 2.80^{\mathrm{b}}$ \\
\hline Pure milk chocolate $(0: 100)$ & $27.48 \pm 0.00^{d}$ & $37.13 \pm 0.64^{b}$ & $29.96 \pm 0.00^{d}$ & $8.85 \pm 0.78^{b}$ \\
\hline
\end{tabular}

a,b,c,d Different letter indicates significant different between rows under same column

Table 5 Composition of fatty acid (\%) in the compound and pure milk chocolate

\begin{tabular}{llllllllllll}
\hline \multirow{2}{*}{ Formulations (CBS: CB) } & \multicolumn{10}{c}{ Composition of fatty acid (\%) } \\
\cline { 2 - 12 } & $C_{8}$ & $C_{10}$ & $C_{12}$ & $C_{14}$ & $C_{16}$ & $C_{16}: 1$ & $C_{18}$ & $C_{18}: 1$ & $C_{18}: 2$ & $C_{18}: 3$ & $C_{20}$ \\
\hline $100: 0$ & 3.02 & 2.91 & 41.15 & 14.51 & 10.18 & - & 18.2 & 7.15 & 2.39 & 0.24 & 0.25 \\
$80: 20$ & 2.6 & 2.54 & 36.45 & 12.73 & 12.76 & 0.06 & 22.11 & 8.81 & 1.34 & 0.14 & 0.4 \\
$60: 40$ & 1.74 & 1.67 & 23.77 & 8.39 & 16.2 & 0.1 & 22.18 & 20.19 & 4.64 & 0.47 & 0.55 \\
$40: 60$ & 1.89 & 1.84 & 26.43 & 9.35 & 15.06 & 0.09 & 20.5 & 18.58 & 5.17 & 0.54 & 0.48 \\
$20: 80$ & 0.23 & 0.2 & 2.88 & 1.14 & 23.5 & 0.2 & 30.68 & 33.84 & 5.63 & 0.52 & 0.99 \\
$0: 100$ & 0.22 & 0.2 & 2.12 & 0.83 & 23.43 & 0.2 & 30.96 & 34.23 & 5.83 & 0.55 & 1.01
\end{tabular}

*FAC, fatty acid composition; $C_{8}: 0$, caprylic acid; $C 10: 0$, capric acid; $C_{12}: 0$, lauric acid; $C_{14}: 0$, myristic acid; $C_{16}: 0$, palmitic acid; $C_{16}: I$, palmitoleic acid; $C_{18}: 0$, stearic acid; $C_{18}: I$, oleic acid; $C_{18}: 2$, linoleic acid; $C_{18}: 3$, linolenic acid; $C_{20}: 0$, arachidic acid

CBS is a rich source of lauric acid, $\mathrm{C}_{12}(48.3 \%)$ and other major fatty acids such as myristic acid, $\mathrm{C}_{14}(15.6 \%)$, and oleic acid, $\mathrm{C}_{18}: 1$ $(15.1 \%)$. The level of fatty acids such as lauric $\left(C_{12}\right)$ and myristic $\left(C_{14}\right)$ was present in $\mathrm{CB}$ as a trace or very low amount whereas the amount of palmitic $\left(\mathrm{C}_{16}\right)$, stearic $\left(\mathrm{C}_{18}: 0\right)$, and oleic $\left(\mathrm{C}_{18}: 1\right)$ acids was high. The different composition of fatty acid might be due to the blending of two fats from different sources i.e. CBS and CB. The ratio 100: 0 (CBS:CB) contain about $40 \%$ of lauric acid and about $10 \%$ of palmitic acid in CBS made from hydrogenated palm kernel oil (HPKO). ${ }^{23,31,32}$ Although CBS contains a high level of lauric and myristic acid, it is widely used as a suitable raw material in confectionery. ${ }^{33}$ Therefore, the compound milk chocolate containing $20 \% \mathrm{CBS}$ and $80 \% \mathrm{CB}$ $(20: 80)$ shows similar fatty acids composition as pure milk chocolate.

\section{Conclusion}

In this study, the different composition of $\mathrm{CBS}$ and $\mathrm{CB}$ in milk chocolates significantly $(\mathrm{p}<0.05)$ affected the product quality characteristics. The ratio 20:80 (CBS: CB) compound milk chocolate had similar characteristics with pure milk chocolate in terms of fatty acid composition (lauric acid 2.88\%) and hardness (2832.3 \pm 8.88 ). The suitable blend of compound chocolate may provide the best alternatives for the chocolate producer.

\section{Acknowledgements}

The authors appreciate financial support from Universiti Putra Malaysia (UPM) and Barryl Callebaut Asia Pacific Sdn Bhd for supplying materials and their cooperation. 


\section{Conflict of interest}

The author declares that there is none of the conflicts.

\section{References}

1. Jahurul MHA, Zaidul ISM, Norulaini NAN, et al. Cocoa butter fats and possibilities of substitution in food products concerning cocoa varieties, alternative sources, extraction methods, composition, and characteristics. Journal of Food Engineering. 2013;117(4):67-476.

2. Smith KW, Cain FW, Talbot G. Nature and composition of fat bloom from palm kernel stearin and hydrogenated palm kernel stearin compound chocolates. Journal of Agriculture and Food Chemistry. 2004;52(17):5539-5544.

3. Schmelzer JM, Hartel RW. Interactions of milk fat and milk fat fractions with confectionery fats. Journal Dairy Science. 2001;84(2):332-344.

4. Lonchampt P, Hartel RW. Fat bloom in chocolate and compound coatings. European Journal of Lipid Science and Technology. 2004;106(4):2414247 .

5. Lipp M, Anklam E. Review of cocoa butter and alternative fats for use in chocolate-Part A: Compositional data. Food Chemistry. 1998;62(1):7397.

6. De Clercq N, Moens K, Depypere F, et al. Influence of cocoa butter refining on the quality of milk chocolate. Journal of Food Engineering. 2012;111(2):412-419.

7. Talbot G, Smith KW. The Nature of Fat Bloom on Lauric Compound Coatings. Consultants to Loders Croklaan. 2004. p. 1-7.

8. Afoakwa EO, Paterson A, Fowler M, et al. Flavor formation and character in cocoa and chocolate: a critical review. Critical Reviews in Food Science and Nutrition. 2008;48(9):840-857.

9. Vasanthan T, Bhatty RS. Physicochemical properties of small and largegranule starches of waxy, regular, and high-amylose barleys. Cereal Chemistry. 1996;73(2):199-207.

10. Afoakwa EO, Paterson A, Fowler M, et al. Relationship between rheological, textural and melting properties of dark chocolate as influenced by particle size distribution and composition. European Food Research and Technology. 2008;227(4):1215-1223.

11. AOCS. Separation of fat in cacao products. In: Association of Official Analytical Chemists, official methods of analysis. USA: Arlington, Official Methods; 2002.

12. Hogenbirk G. Compatibility of specialty fats with cocoa butter. Manufacturing Confectionary. 1984;64:59-63.

13. Noorden AC. Fat bloom-causes and prevention when using lauric hard butters. Susswaren Tech. 1982;26:318-322.

14. Williams S, Ransom Painter K, Hartel R. Mixtures of palm kernel oil with cocoa butter and milk fat in compound coatings. Journal American Oil Chemist's Society. 1997;74(4):357-366.

15. Afoakwa EO, Paterson A, Fowler M. Factors influencing rheological and textural qualities in chocolate-a review. Trends in Food Science and Technology. 2007;18(6):290-298.

16. Liesbeth $\mathrm{D}$. The use and applicability of cocoa butter equivalents (CBEs) in chocolate products. Faculteit Bio-ingenieurswetenschappen, Universiteit Gent. 2011. p. 1-103.
17. Tabouret T. Detection of fat migration in a confectionery product. International Journal of Food Science and Technology. 1987;22(2):163167.

18. Ziegleder G, Schwingshand I. Kinetik der Fet, igration in Schokoladenprodukten. Teil III: Fettreif. Fett-Lipid. 1998;100:411-415.

19. Walter P, Cornillon P. Influence of thermal conditions and presence of additives on fat bloom in chocolate. Journal of the American Oil Chemists' Society. 2001;78(9):927-932.

20. Walter P, Cornillon P. Lipid migration in two-phase chocolate systems investigated by NMR and DSC. Food Research International. 2002;35(8):761-767.

21. Mc Farlane I. Instrumentation. In: ST Beckett editor. Industrial chocolate manufacture and us. USA: Chapman \& Hall; 1999. p. 347-376

22. Abdulkarim SM, Ghazali HM. Comparison of Melting Behaviors of Edible Oils Using Conventional and Hyper Differential Scanning Calorimetric Scan Rates. ASEAN Food Journal. 2007;14(1):25-35.

23. Wang F, Liu Y, Shan L, et al. Blooming in cocoa butter substitutes based compound chocolate: Investigations on composition, morphology and melting behavior. Journal of the American Oil Chemists' Society. 2010;87(10):1137-1143.

24. Huyghebaert A, Hendrickx H. Polymorphism of cocoa butter shown by differential scanning calorimetry. Lebensmittel-Wissenschaft undTechnologie. 1971;4:59-63.

25. Smith KW. Cocoa Butter and Cocoa Butter Equivalents. In: Gunstone F editor. Structured and Modified Lipids. Bedfordshire: Unilever Research Colworth; 2001. p. 401-422.

26. Aidoo RP, De Clercq N, Afoakwa EO, et al. Optimization of processing conditions and rheological properties using Stephan Mixer as conche in small-scale chocolate processing. International Journal of Food Science and Technology.2014;49(3):740-746.

27. Talbot G. Formulation and Production of Confectionery Fats. OFI Middle East 2007 Conference and Exhibition. 2007.

28. Nieburg O. Price pressure: Will chocolate makers bite the bullet on cocoa butter alternatives? Confectionariy news.com. News \& analysis on chocolate, candy and biscuits. 2014.

29. Chaiseri S, Dimick PS. Lipid and hardness characteristics of cocoa butters from different geographic regions. Journal of the American Oil Chemists' Society. 1989;66(12):1771-1775.

30. Simoneau C, Hannaert P, Anklam E. Detection and quantification of cocoa butter equivalents in chocolate model systems : analysis of triglyceride profiles by high resolution GC. Food Chemistry. 1999; 65(1):111-116.

31. Ransom Painter KL, Williams SD, Hartel RW. Incorporation of milk fat and milk fat fractions into compound coatings made from palm kernel oil. Journal Dairy Science. 1997;80(10):2237-2248.

32. Sabariah S, Ali ARM, Chong CL. Chemical and physical characteristics of cocoa butter substitutes, milk fat and malaysian cocoa butter blends. Journal American Oil Chemist Society. 1998;75(8):905-910.

33. Pantzaris TP, Ahmad MJ. Properties and utilization of palm kernel oil. Palm Oil Developments. 2001;35(11-15):19-23. 